\title{
Evidence-based medicine in primary care: qualitative study of family physicians
}

\author{
C Shawn Tracy ${ }^{1}$, Guilherme Coelho Dantas ${ }^{1,2}$ and Ross EG Upshur*1,2
}

Address: ${ }^{1}$ Primary Care Research Unit, Sunnybrook \& Women's College Health Sciences Centre, Toronto, ON M4N 3M5 Canada and ${ }^{2}$ Department of Family and Community Medicine, University of Toronto, Toronto, ON M5T 1W5 Canada

Email: C Shawn Tracy - shawn.tracy@sw.ca; Guilherme Coelho Dantas - gui.dantas@utoronto.ca; Ross EG Upshur* -rupshur@idirect.com

* Corresponding author

Published: 9 May 2003

BMC Family Practice 2003, 4:6

This article is available from: http://www.biomedcentral.com/I47I-2296/4/6

(C) 2003 Tracy et al; licensee BioMed Central Ltd. This is an Open Access article: verbatim copying and redistribution of this article are permitted in all media for any purpose, provided this notice is preserved along with the article's original URL.
Received: 17 January 2003

Accepted: 9 May 2003

\begin{abstract}
Background: The objectives of this study were: a) to examine physician attitudes to and experience of the practice of evidence-based medicine (EBM) in primary care; b) to investigate the influence of patient preferences on clinical decision-making; and c) to explore the role of intuition in family practice.
\end{abstract}

Method: Qualitative analysis of semi-structured interviews of 15 family physicians purposively selected from respondents to a national survey on EBM mailed to a random sample of Canadian family physicians.

Results: Participants mainly welcomed the promotion of EBM in the primary care setting. A significant number of barriers and limitations to the implementation of EBM were identified. EBM is perceived by some physicians as a devaluation of the 'art of medicine' and a threat to their professional/clinical autonomy. Issues regarding the trustworthiness and credibility of evidence were of great concern, especially with respect to the influence of the pharmaceutical industry. Attempts to become more evidence-based often result in the experience of conflicts. Patient factors exert a powerful influence on clinical decision-making and can serve as trumps to research evidence. A widespread belief that intuition plays a vital role in primary care reinforced views that research evidence must be considered alongside other factors such as patient preferences and the clinical judgement and experience of the physician.

Discussion: Primary care physicians are increasingly keen to consider research evidence in clinical decision-making, but there are significant concerns about the current model of EBM. Our findings support the proposed revisions to EBM wherein greater emphasis is placed on clinical expertise and patient preferences, both of which remain powerful influences on physician behaviour.

\section{Background}

Evidence-based medicine (EBM) has emerged as an influential model for the teaching and practice of clinical medicine. Although the concept has been successfully disseminated in the health care field, there have been numerous criticisms advanced. Arguments have been put forth that EBM represents reductionism by its narrow definition of evidence; ignores the legitimacy of clinical judgement, experience, and the time constraints of nonacademic practice; fails to include and respond to patient values; fosters an inappropriate reliance on epidemiology and statistical methodology, particularly a dogmatic 
adherence to the RCT; lacks empirical justification; and is poorly specified for some aspects of clinical medicine such as primary care [1-7].

The legitimacy of these criticisms has been hotly debated $[8,9]$. Partly in response to the critics and the admitted shortcomings of the original formulation of EBM, there has been a transformation within EBM itself as exemplified by the proposed distinction between evidence-based practitioners and evidence users [10] and the newly-articulated framework highlighting the interaction among clinical expertise, patient preferences and values, research evidence, and clinical state and circumstances [11]. These significant modifications to the original model indicate that EBM is an evolving methodology currently in transition. Polemics aside, however, there is little empirical evidence of how evidence-based practice is actually perceived by physicians in relation to clinical expertise and patient preferences. Such empirical investigation is essential to harmonising the stated goals of EBM with the realities and expectations of clinicians and patients. Thus, the objective of this study was to investigate physician attitudes to and experience of the practice of EBM in primary care, specifically with respect to the influence of patient preferences and the role of intuition in clinical decision-making.

\section{Methods}

\section{Participants and setting}

This paper reports on the qualitative component of a larger multi-methods project based in the Primary Care Research Unit at Sunnybrook \& Women's College Health Sciences Centre in Toronto, Canada. The study, which was approved by the Research Ethics Board of the host institution, was carried out between July and November of 2002. Previous to this, we had conducted a national survey of
Canadian family physicians on the practice of EBM in primary care; as part of the mail-out package, all survey recipients (target sample $=1134$ ) were additionally invited to participate in a follow-up qualitative study. A total of 64 survey respondents indicated a willingness to be interviewed by signing and returning a reply post-card. The demographic characteristics (age, gender, practice setting) of this sub-set of 64 willing physicians mirrored quite closely those of the overall target sample of 1134 . We purposively sampled from this list to reflect diversity with respect to age, sex, practice setting (urban/rural), and geographic location in Canada (east/west). We contacted a total of 23 physicians to invite their participation in the study; 15 agreed to be interviewed, five did not respond to our invitation, and three were unable to participate owing to time constraints.

Our final sample comprised eight female physicians (53\%) and seven males (47\%). The age distribution of participants was as follows: $27 \%(n=4)$ were $25-39$ years of age; $47 \%(\mathrm{n}=7)$ were aged $40-54$ years; and $27 \%(\mathrm{n}=$ 4 ) were $55+$ years of age. The mean number of years in clinical practice was 16.3 years; the mode was also 16 years. Two-thirds $(\mathrm{n}=10 ; 67 \%)$ of participants reported practicing in urbanized regions, while the remaining onethird $(\mathrm{n}=5 ; 33 \%)$ practiced in rural areas. The majority $(\mathrm{n}$ $=10 ; 67 \%)$ were part of a group practice; three $(20 \%)$ were in solo practice; and two (13\%) practiced exclusively in locums. Most participants $(n=10 ; 67 \%)$ reported having internet access in their office/clinic and most $(n=12$; $80 \%$ ) also reported some degree of involvement in education (teaching of medical students, supervision of residents, etc.). A detailed demographic profile of the 15 individual participants is presented in Table 1.

Table I: Demographic profile of participants

\begin{tabular}{ccccccccc}
\hline Code & Age Group & Sex & $\begin{array}{c}\text { Years in } \\
\text { Practice }\end{array}$ & $\begin{array}{c}\text { Type of } \\
\text { Practice }\end{array}$ & $\begin{array}{c}\text { Practice } \\
\text { Setting }\end{array}$ & $\begin{array}{c}\text { Geographic } \\
\text { Location }\end{array}$ & $\begin{array}{c}\text { Internet at } \\
\text { Office? }\end{array}$ & $\begin{array}{c}\text { Involved in } \\
\text { Teaching? }\end{array}$ \\
\hline FP01 & $25-39$ & M & 4 & Locums & Rural & West & N/A \\
FP02 & $40-54$ & M & 17 & Group & Urban & East & Yes & Yes \\
FP03 & $55+$ & F & 30 & Solo & Urban & West & No & Yes \\
FP04 & $40-54$ & F & 18 & Group & Rural & West & Yes \\
FP05 & $40-54$ & F & 23 & Group & Rural & East & Yes \\
FP06 & $55+$ & M & 35 & Group & Urban & East & No \\
FP07 & $40-54$ & F & 7 & Group & Rural & West & No \\
FP08 & $40-54$ & M & 12 & Solo & Urban & West & Yes \\
FP09 & $25-39$ & F & 4 & Group & Urban & East & Yes & Yes \\
FPI0 & $55+$ & F & 32 & Group & Urban & East & Yes \\
FPII & $25-39$ & F & 2 & Locums & Urban & East & N/A \\
FPI2 & $25-39$ & M & 2 & Group & Urban & East & Yes \\
FPI3 & $40-54$ & M & 16 & Group & Rural & East & Yes \\
FPI4 & $55+$ & M & 28 & Solo & Urban & West & Yes \\
FPI5 & $40-54$ & F & 14 & Group & Urban & West & Yes \\
\hline
\end{tabular}




\section{Data collection and analysis}

We employed a grounded theory approach, which is particularly well-suited to exploratory studies of this nature [12]. Two of the authors (CST and GCD) shared the task of conducting the interviews based on a random assignment of participant to interviewer. We utilized a semistructured interview schedule that was developed with input from researchers and academic clinicians and then pilot-tested on three primary care physicians at the host institution. All interviews were conducted by telephone and were audio-taped with the participants' consent; the interviews typically lasted between 30 and 40 minutes. Data collection continued until there was agreement among all three authors that saturation had been reached.

Each interview was transcribed verbatim, following which the accuracy of the transcription was verified by the interviewing author (to allow for clarification of any inaudible passages). The first two authors independently read and coded each successive transcript as it became available and organized the data into broad theoretical categories. In order to test for credibility, emerging themes from the early interviews were explored in subsequent interviews, consistent with the 'constant comparative method' [13].

At the completion of data collection, the first two authors (CST and GCD) each prepared a list of main themes and representative quotations for purposes of comparison. Instances of disagreement were resolved through a process of discussion and negotiation that included the third member of the research team (REGU). Throughout the analysis process, we maintained a conscious search for contradictory cases. Our analysis of the data yielded six major substantive themes which are presented below.

\section{Results \\ Benefits and barriers}

The vast majority of respondents welcomed the promotion of EBM in family practice; however, participants also enumerated a significant list of barriers and limitations pertaining to implementation (Table 2). Among the many perceived benefits of EBM were improved standards of care, enhanced doctor-patient communication, superior formatting of information, and decreased complacency regarding practice patterns. At the same time, there was a widely-shared belief, even among some of those who most welcomed the introduction of EBM, that the initiative did not reflect a genuine paradigm shift in the practice of clinical medicine, but rather reflected a "rebranding" of sorts. Several physicians explained how they utilise research evidence to provide patients with treatment options; others reported using the evidence to justify their clinical decisions.
The most commonly mentioned barrier to the practice of EBM was insufficient time owing to an extremely heavy workload. Limited resources and a lack of local specialists were also common concerns, particularly among rural physicians. The majority of respondents pointed to the problem of generalizability as an important limitation of EBM as it is currently structured. Finally, there were a number of barriers pertaining to issues of access. A small minority reported having no or limited access to the Internet at their office; those with easy access complained that it is often difficult to find information and that, once found, it is typically not in user-friendly formats.

\section{Constraints on practice}

Despite generally positive views, EBM is perceived by some as a devaluation of the 'art of medicine' or a threat to their clinical autonomy, or both (Table 3). Participants expressed concern that EBM is leading to less flexibility and less room for creative problem-solving in family practice. Evidence-based guidelines were described as a constraining force on family physicians; one physician expressed her fear of forced adherence to guidelines and another believes that her competency is doubted when she deviates from the evidence. On the other hand, when prompted, a small number of respondents indicated that they do not share these views or experiences.

\section{Trust and credibility}

There was a tremendous level of concern on the part of respondents with respect to issues of credibility, bias, and the trustworthiness of evidence (Table 4). This anxiety was most readily apparent in physicians' expressions of unease and apprehension regarding the role of the pharmaceutical industry in the funding and conduct of clinical research. Many interviewees specifically decried the growing influence of pharmaceutical manufacturers on decisions about the type of trials that get funded and the sort of findings that get published; indeed, the consensus was that there is an overwhelming need for more independent research to reduce industry bias.

\section{Conflicts and decision-making}

All participants reported the experience of conflicts in their efforts to practice EBM (Table 5). After having considered the available research evidence, it is not uncommon for physicians to act contrary to evidence, most typically because they deemed the results to be inapplicable to the present clinical context. Also, it would appear that patients' preferences are often at odds with the evidence and that in these cases physicians are inclined to act in accordance with the wishes of patients. A third type of conflict arises when there is no clear consensus within the literature - either there is directly conflicting evidence or a consensus is only beginning to emerge. In such cases, 
Table 2: Quotations: Benefits and barriers

\begin{abstract}
"Throughout my residency, EBM was certainly spoken of a great deal ... and I was quite an advocate, but it has been tough to put it into practice in the real world. So maybe it was a little over-touted or maybe it's just growing pains, I'm not sure which, but it's still early days. I think that it's still too early to write it off; I still have hopes for it myself. I think it's philosophically the way to go, but the tools for putting it into practice have yet to be adequately developed." FPOI

"I don't think you sell out all your other methods for evidence-based medicine. You can't just practice exclusively evidence-based medicine, or else you'll miss out on some things. Having said that, however, I do support more use of it, especially for the initial management of common problems... It's very useful to have an evidence-based structure because you often have undifferentiated presentation at the outset. As you follow the course of an illness, then you have more individual solutions." FPI2

"It's a buzzword. Maybe they used a different word before. We always had to have evidence that things work before you put them in practice, right? You never did something unless you had evidence. In the '70s, I always looked at what evidence there was from clinical trials and clinical practice guidelines before I implemented." FP I 4

"For family medicine, I think that we now have something to base our approaches on rather than just sort of general nice feelings. We have a more organized way, particularly from a teaching point of view, of how to approach problems.... I think [EBM] is probably the only way to go now, given that we have access to such a mountain of information." FPIO

"Evidence-based medicine seems to be a word that has become very fashionable, and in many ways, I wonder how it is different than the medicine that I learned 30 years ago. To me, it means that there is evidence to show that something is effective and I thought that that's what we did all along... I haven't seen anything in it that convinces me that it's a huge paradigm shift." FP06

"I think it's really important. I try to be evidence-based as much as I can ... and I try to stay up to date. I try to explain things to patients, because they don't always understand, particularly if I'm doing something that they don't expect. Then I'll try to explain to them that there's evidence for doing or not doing something." FPI I

"I think it's good, because it actually protects us. If we're ever accused or criticized for the practice that we're performing and we can go back to the studies and say, 'Here's the evidence that suggests this is the best way to treat it.' That protects you from a medical/legal point of view and it also allows you to reassure the patient that the practice you're pursuing is based on evidence that's been gleaned by good quality studies." FP08 "I think it [EBM] needs distillation. It's difficult to apply in family practice because there are a gazillion guidelines out there, all purporting to be based on the evidence." FP05

"I think EBM is predicated upon there being well-supported and financed independent reviewers who are doing the meta-analyses and the broader views which have become the key to evidence-based medicine and then selecting which ones are quality enough to include. It's just not practical for the family practitioner to be able to do that, even if you do have the tools, the time just isn't going to be there." FPO I

"One problem is when we take on some EBM evidence, our patients may not fit into the sample that was studied. Part of the challenge I have is trying to remember who was in the studies and who it applies to. You know, I'm not going to go look up every single study every time I want to apply some of the literature to my patients. I think that's definitely a factor." FP09

"I think for the average practitioner, EBM has limited applicability or practicality in its current format. It has to be changed if it's going to be practical for use by most family doctors." FP02

"I think that you still have to consider expert opinion, because you have to rely on the experts to evaluate what the literature shows, to give you some kind of impression overall, like how applicable it is to other people. I don't think that the individual standardly trained physician that's working in the community has the time or training or interest to decide what's good evidence and what isn't. So I think you still need the experts." FP09 "A lot of times the findings of these large clinical trials are indiscriminately applied to a population that it doesn't apply to. I'm very critical of that. I'm sort of on hyper-alert for not doing that.... I wouldn't want to be treated exactly the same way as 10 million other people simply because for 90 percent of people this works. What if I'm one of the other 10 percent?" FP06

"It's difficult to adopt evidence-based medicine in primary care when every patient needs to have every investigation that you think is appropriate. So, I'm always making judgments and yet trying to keep in mind the fact that there are some things I shouldn't do because the evidence isn't there for it." FP03

"It's very difficult right now because the resources are poor and the funding for family physicians is targetted towards solving problems rather than practicing evidence-based medicine. We are paid to put out fires, if I might say so. We don't get enough time to practice evidence-based medicine in terms of prevention." FPI4

"I do not offer colon cancer screening to my patients, for instance. The evidence is there that it helps, but I don't have the time to go through it and we don't have the colonoscopy backup - it just isn't available here." FP05
\end{abstract}

the majority of respondents rely on past practice to inform their decision-making.

\section{Patient factors}

Patient preferences, values, and expectations appear to exert a tremendous influence on the clinical decisionmaking of these family physicians (Table 6). Many participants noted that patient preferences can and often do determine the direction of the treatment plan. Indeed, most of the physicians in our sample reported that when patient preferences directly collide with other factors - whether it be evidence from published studies, local practice patterns, etc. - the tendency is to do what the patient wants. On the other hand, a small number of participants expressed a reluctance "to give in to the patient." Managing patient preferences/expectations is seen as one aspect of the 'art of medicine' that many participants referred to as a casualty of the increasing reliance on EBM.

\section{The role of intuition}

There was overwhelming agreement that intuition plays a vital role in the practice of family medicine (Table 7). 
Table 3: Quotations: Constraints on practice

\begin{abstract}
"I fear that what's happening with evidence-based medicine is that it's becoming a rigid system and the push behind evidence-based medicine in certain quarters, not all, has to do with money and not with care... There is less of an understanding on the part of management of the actual work circumstances for those of us on the care end that are trying to implement it." FP04

"I think my practice is more evidence-based than it was because the information is more widely available. I guess the difficulty is that when I'm seeing patients, I don't want to be totally constrained by this idea that the only thing you can do in any one encounter is what's defined by a guideline, and if it's not defined by a guideline, then you can't do it." FP03

"I think evidence-based medicine is being over-emphasized. We're losing the art of medicine.... We're becoming too much like paper pushers and computer geeks instead of recognizing the humanity, especially with family physicians who see the people through everything." FP07

"I think the fear that I have about evidence-based medicine is that it's asking us not to think any more. If somebody else is going to go, "Okay, we've looked at the evidence and this is what you do," then I'm becoming more of a technician than a practitioner. I do think that there's still a place for us to be critical of evidence." FP04

"The guidelines will only take you so far and they're a useful stepping off point, but each individual case has so many factors at play beyond what the guidelines cover and that's where the art and the pleasure of medicine comes in using your clinical judgement to realize that what the protocol says doesn't apply to that person or it applies in a different way. That takes a good understanding of what the meaning is behind the protocol so I don't think you're ever just a technician." FPOI

"The way it's presented is: 'This is what you do. If this is here, you do that.' That's not the way we can practice medicine and they have to realize that." FPIO

"I have to say that, probably because I practiced before it came along, I know that most of the things that I do are not evidence-based... Personal experience means a lot and it's hard to get away from that when you're faced with an evidence-based pronouncement that says that a certain thing that you do for somebody isn't useful, even though you've used it in the past and found something that you wouldn't have found if you hadn't done it." FP03

"Another frustration would be that when a patient doesn't respond well to a certain therapy, then we need to use other therapies, but there may or may not be evidence for that. Then sometimes we're checked or doubted for our competency if we do things not quite in the norm." FP07 "We get mail-outs of clinical practice guidelines which are evidence-based - they're really looked at as recommendations for treatment. None of us feel like we have to do things this way, but we also know that we have information on a simple sheet to back up where the evidence is." FP08
\end{abstract}

\title{
Table 4: Quotations: Trust and credibility
}

\footnotetext{
"This is where I have a real problem. The evidence base is driven by profit. More and more, it's driven by profit. Nobody's doing the studies with medications that already exist but are off patent. Nobody's doing the studies with simple interventions like making sure that single moms have relief. So if I just go by what there's evidence for, I end up participating in this industrial complex." FP05

"Something I'm intensely aware of at all times is the degree to which the information source is promoting a drug company agenda. Certainly with all the freebie journals that we get I look at them with an extremely skeptical eye to the point of not even looking at them for the most part, but they do have the occasional useful bit so I tend to filter very, very heavily." FPO I

"The absolute worst are new drug trials... It's very typical that these are funded by drug companies. They're low quality, not taking into account side effects of the drugs, there's not a long enough follow-up so that you could properly judge whether the drug is safe or not, and they use ways of assessing effectiveness that favour the drug." FP02

"It would be nice if there was more pure research done through academic agencies who are independent of drug companies. Then you wouldn't have to worry about removing that one bias - it just wouldn't be there to begin with... In the real world, drug companies are going to be funding a lot of the research, so you've got to be aware of that all the time as a clinician down at my end, far removed from the research." FP I3

"I think it can limit advancement because a lot of the 'evidence-based medicine' is conducted by drug companies, and I have a big issue about that.... I think it's unfortunate that drug companies have so much influence on the things that are studied. For instance, I think natural therapies and complementary therapies is one area that really needs to be researched, but it probably won't because they can't get patents on it." FP07

"I think EBM is predicated upon there being well-supported and financed independent reviewers who are doing the meta-analyses and the broader views which have become the key to evidence-based medicine." FPOI

"I don't want to transfer authority from the individual physician to the pharmaceutical companies or to the vested interests and I think that's what we're in danger of doing. The evidence isn't clean, so much so now that respected journals are struggling not to accept tainted evidence and still keep their heads above water. There are terrible influences on them." FP05

"In my view, not all publications are equal in that those published by drug companies and those in more marginal journals are frequently more marketing than they are true science. Even with those of quite high quality, they often go through huge amounts of selection with inclusion/exclusion criteria such that the results are probably most applicable to only a small portion of a family doctor's population, but that is not stressed enough in the papers. The results and the discussion tend to focus mostly on the successful nature of the medication without incorporating enough of the appropriate cautions and limitations of where this information should be applied." FP02

"The difficult problem with evidence-based medicine is that in order to produce a high quality trial you need to have a certain amount of funding and there are probably ways that things can be manipulated so that you can get that trial off the ground and published with a particular result.... Then there are the pharmaceutical companies, which choose not to publish results of trials they've conducted that don't show a difference. They just won't get seen. So you can't put all your eggs in the basket of evidence-based medicine." FP I 2
} 
Table 5: Quotations: Conflicts and decision-making

\begin{abstract}
"Oh, we have examples of that daily. For instance, the patient thinks he must have a PSA. The evidence is not clear that that's going to save his life. In fact, it may render him incontinent and impotent for something that may not have bothered him at all." FP05

"There's tons of examples [of conflicts] at the moment. What about mammography and breast self-exam? Patients are as confused as family doctors are. I think it shows that science can only take us part of the way." FP04

"With evidence-based medicine, you're looking at the methodology. You're seeing how closely a patient fits with the particular study and many times your specific situation does not fit exactly. Then you're using clinical insights, you're using patient preferences, you're using your own experience, you're using the practice patterns of your community... Certainly, I think it behooves one to be aware of what the evidence is, but that doesn't mean that even though there's good evidence available that that's going to be the best answer in your specific situation." FPI 2

"It's pretty common that it happens [conflicting evidence] and it's a very difficult challenge. For the most part, the patients are usually informed of a conflict and they often ask what my opinion is, which I think is very interesting because EBM is telling us not to have opinions about it, but yet the patients are actually wanting our opinions." FP09

"When you've worked the number of years I have, you go with something you're familiar with. If there's two medications and you're not sure, you tend to stick with what you are familiar with, whether there's good evidence or not, I'm afraid. I go with what I know and what I've practiced - you might call it intuition." FPIO

"In those cases [conflicting evidence], it's hard to know what to believe sometimes, but you just evaluate the evidence that's there and wait for better evidence.... I often ask for advice, usually from family physicians. Then also, although I don't have a lot of experience, you're also looking at your own experience, which I know is not great evidence [laughs], it's anecdotal evidence, but it sometimes does play a part." FP I I

"When you've got conflicting results from evidence-based medicine - you've got evidence saying one thing and evidence saying the exact opposite thing - you're going to have to use other bits of information or strategies to try to decide which way you're going to go." FP I 2

"I can see lots of conflict between the goals of a study and the goals in real life." FP06
\end{abstract}

While the definitions varied from one physician to the next, a recurring element was that intuition has its origins in personal clinical experience. Even those participants who argued in favour of the promotion of EBM and described themselves as evidence-based practitioners included intuition among the necessary tools for strong clinical decision-making. Indeed, EBM and intuition were perceived as complementary rather than opposing one another. Many respondents referred to research evidence as a 'starting point' - it was not thought of as 'a bible.'

\section{Discussion}

Primary care physicians appear to value the principle of clinical decision-making informed by research evidence, but there exist many significant concerns pertaining to conflicts, implementation barriers, bias, clinical autonomy, and scientific reductionism. The overall sentiment toward EBM in this sample of family doctors might best be characterized as 'guarded optimism.' We also discovered that primary care physicians place great value in the role of intuition in clinical decision-making.

The strength of our study derives from the sample, which was comprised of male and female family physicians of all age groups from across Canada in both urban and rural settings, solo and group practices, and with a wide range in years of clinical experience. Our study is limited because the interviewees were initially self-selected from among approximately 1150 physicians invited to participate in a national postal survey. We cannot, therefore, be certain that our sample is representative of the population of Canadian family physicians (despite a concerted effort to maximise representativeness by seeking participants of various age groups, practice settings, geographic locations, etc.). It does appear that the percentage of physicians in our sample who are involved in teaching activities (80\%) is out of proportion to that of the wider Canadian physician population (25\%) [14]. At the same time, while an academically-inclined sample is likely to be better informed about EBM, it not necessarily more receptive or more opposed; that is to say, the bias is likely non-directional.

Our data is consistent with previously published studies indicating that physicians hold mixed views toward the promotion of EBM in primary care. For instance, a postal survey of British general practitioners revealed that while the majority are welcoming of EBM, only a very small proportion (5\%) believe that the most appropriate method of moving towards EBM is for primary care physicians to learn the necessary skills (i.e., identifying and appraising the scientific literature) [15]. Likewise, the findings of a qualitative study of general practitioners in three Australian cities suggested that the majority are simply not interested in learning the fundamental skills of critical appraisal [16]. It is not surprising then that the EBM skills of primary care physicians tend not to be particularly well developed $[17,18]$.

Our study also reinforces that there are a number of structural barriers to the implementation of EBM - many of which are unique to the primary care setting [19-21]. A recent Canadian study of the role of evidence in primary care found that while family physicians are increasingly making use of clinical research findings in the course of 


\begin{abstract}
"Sometimes it's hard to sell it [the evidence] to certain patients. They have a certain expectation and one of the principles of family medicine is to be patient-centred. You have to listen to what they have to say and then meet in the middle... Often it's a struggle and I find that l'm delaying treatment because the patient is not willing to accept the evidence" FP09

"I try to explain the evidence to them as best I understand it, and then we end up doing what the patient wants to do most of the time." FP05 "It [EBM] has to be another layer of thinking, I suppose, but when it comes to whether or not it's in the patient's best interest to do it, the evidencebased stuff often goes out the window... I think it's useful to have it as a guideline, but it's difficult sometimes when you think you're in the hot seat trying to deal with a patient's needs. You don't want to let your patient down... and sometimes that's a difficult task to accomplish, to have the patient go away feeling that their concerns have been addressed." FP03

"Sometimes, in order to keep the peace, you may deviate from the evidence to appease the patient. You have to do that sometimes because you're living in the real world, you're interacting with people. The trick is to know how far you can deviate." FP I 3

"EBM is helpful to give physicians a reference on how to manage cases, but it depends on the personality of the patient. When I know the patient, they're usually willing to accept it [the evidence]. It's important to earn the trust of the patient first." FP I 5

"Evidence-based medicine has probably been over-focused on the scientific data aspect and less about how to incorporate that in the context of the patient's values and wishes and the particular clinical circumstances of a given individual patient." FP02

"Patients are now accessing the Internet and coming in with decisions about what's wrong with them. With a certain set of symptoms, one would follow a certain protocol for testing, but sometimes now patients have ingrained in themselves the idea that they have to have this [particular treatment], and there's no amount of discussion that will budge the feeling that that's what they've got. So, in that circumstance, I will sometimes order the test they're asking for, even though they don't fit the protocol, because that's the only way of showing to them that that firmly held belief that this is what's wrong with them isn't what's wrong with them." FP04

"What I explain to my patients is that my job is to give them advice, and my advice is based on the best evidence and skill that I have, and then once they listen to my advice, they have to make up their own mind and take my advice and do whatever they want with it. If they insist on having something more aggressive done that I don't agree with, then I'll often set up for them to get a second opinion." FP08

"I often negotiate with the patient. If there's some kind of end-point we're looking at, depending on what they're wanting to do, and if it seems reasonable and non-harmful, I'll often go along with something I normally wouldn't, for a while anyway... I think it really depends on the situation. I think the bottom line is looking at what's more harmful to the patient. I really try to talk with the patient about it beforehand That's where the art comes in. If the patient is very articulate and has read up on different information, then I'll go along with it to a point, but I won't go against my own ethics or the College ethics." FP07

"The evidence that new drug XYZ is going to reduce the incidence of death by one percent really doesn't matter if my patient can't afford the basic... If it's something like a minor improvement for a great deal of money, I won't even tell the patient. What's the point? I know they can't afford it." FP05

"What is it that you want to achieve? Are you looking at quantity of life or quality of life? And how do people value of quality of life? What's important to them? Those are things that need to be factored in. If you specifically want to look at avoiding heart attacks, maybe you can avoid somebody from having an M.I. and get them to live to II 0 , but if what they have to do makes them miserable for the next 30 years, you've achieved the stated outcome, but that's not really in synchrony with what the patient desires. Then there's the whole issue of the patient, the family, society - it gets very complex." FP06

"I listen to my patients and I tend to not push them too much, because they're just going to walk out of there and not be compliant. So I think I have to be realistic as to what I expect that they're going to follow when they leave the office. I guess I try to put it in some context that is going to be meaningful to them in that situation, and paint a picture of both sides of what would happen if they followed the evidence and what would happen if they didn't. I try to sometimes let the patient make the decision of which way they'd like to go - obviously with what I feel would be the most appropriate treatment, but in the end it has to be their decision."FP09

"Sometimes you actually get into arguments with patients, and that's stressful. Most of the time I don't give in to the patient. I try to explain it and either they come on side and sort of agree with me or they totally disagree and they probably go and seek care elsewhere, which happens sometimes with the bigger conflicts." FPI I
\end{abstract}

daily practice, such evidence is not viewed as absolute but rather is considered in conjunction with a diversity of other factors [22].

Clinical decision-making is indeed a complex, multi-factorial process. Despite this, the architects of the original EBM paradigm explicitly downplayed several significant components of the decision-making process: "Evidencebased medicine de-emphasizes intuition, unsystematic clinical experience, and pathophysiologic rationale ... and stresses the examination of evidence from clinical research" [23]. The findings of this study indicate that primary care physicians see no opposition between research evidence and clinical intuition, nor do they believe that evidence always trumps experience, particularly in cases where the evidence is contradictory or patients are expressing strong preferences. Greenhalgh has called for the integration of the 'science' of EBM with the intuitive 'art' of clinical judgement: "It is now time to raise the status of intuition as a component of expert decision-making" [24]. These results provide the first indication that clinical intuition is valued by clinicians on par with research evidence.

The present results also indicate a deep-seated sense of unease with the credibility of research evidence provided or sponsored by pharmaceutical companies. Concerns pertaining to the credibility and trustworthiness of available evidence are highly troublesome for primary care physicians attempting to make evidence-based decisions. 
Table 7: Quotations: Role of intuition

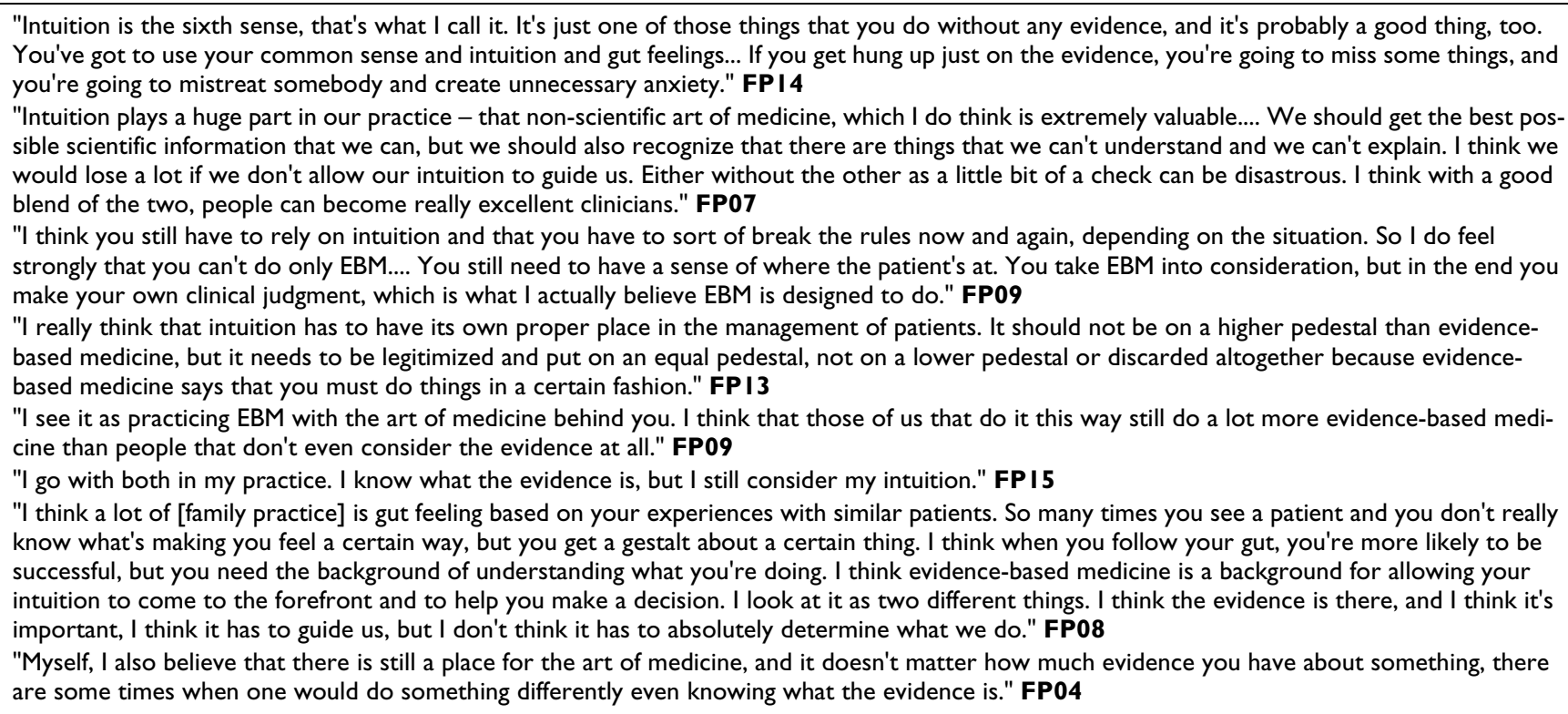

Clearly, more must be done to secure credibility of research evidence. Additionally, patient preferences and expectations appear to exert an important influence on clinical decision-making. Further exploration of the interactions among patient preferences, clinical intuition, and the credibility of research evidence is required.

We conclude that the findings of this study provide empirical support to recent revisions to the EBM model of clinical decision-making that places increased emphasis on the clinical context and patient preferences and actions [11]. Patient preferences clearly play a role in the shaping of clinical decisions - indeed, we have shown that patient factors can serve as trumps to research evidence - and are therefore fundamental to any model of clinical decisionmaking. Perhaps most notable, however, is that where once the value of intuition and clinical experience was explicitly de-emphasized by the proponents of EBM [23], the role of individual clinical expertise now figures most prominently in their revised model [11]. To be sure, the evidence is mounting that intuition is an indispensable element of clinical decision-making in primary care.

\section{Competing interests}

None declared.

\section{Authors' contributions}

REGU initiated and designed the study and is guarantor. CST and GCD recruited the participants, conducted the interviews, and performed the data analysis. REGU participated as a reliability check in the process of data analysis.
CST prepared the first draft of the manuscript. CST, REGU, and GCD contributed to the editing and revising of the paper. All authors have read and approved the final version.

\section{Acknowledgements}

This research was supported by HEALNet (Health Evidence Applications and Linkage Network), a member of the Networks of Centres of Excellence program (1995-2002), which is a unique partnership among Canadian universities, Industry Canada, and the federal research granting councils. REGU is supported by a New Investigator Award from the Canadian Institutes of Health Research (CIHR) and a Research Scholar Award from the Department of Family and Community Medicine.

The authors gratefully acknowledge our peer reviewer, Dr. Jane Young, for her perceptive insights and constructive comments. Without the 15 family physicians who contributed their valuable time and effort, this study would not have been possible. We would also like to thank Shari Gruman for her expert assistance in preparing the manuscript and Jennie Jones for meticulously transcribing the interviews. A final word of thanks to the pilot-test participants - Dr. lan Arnold, Dr. Leslie Nickell, and Dr. Evelyn Williams for their helpful comments and suggestions regarding the interview guide.

\section{References}

I. Lancet: Evidence-based medicine, in its place. Lancet 1995 , 346:785.

2. Charlton BG: Restoring the balance: evidence-based medicine put in its place. J Eval Clin Pract 1997, 3:87-98.

3. Miles A, Bentley P, Polychronis A and Grey J: Evidence-based medicine: why all the fuss? This is why. J Eval Clin Pract 1997, 3:83-6.

4. Miles A, Bentley P, Polychronis A, Grey J and Price N: Advancing the evidence-based healthcare debate. J Eval Clin Pract 1999, 5:97-10I.

5. Tonelli MR: The limits of evidence-based medicine. Respir Care 200I, 46: I 435-40. 
6. Malterud K: The legitimacy of clinical knowledge: towards a medical epistemology embracing the art of medicine. Theor Med 1995, 16:183-98.

7. Tanenbaum SJ: What physicians know. N Engl J Med 1993, 329:1268-7I.

8. Straus SE and McAlister FA: Evidence-based medicine: a commentary on common criticisms. CMAJ 2000, 163:837-4I.

9. Buetow S: Beyond evidence-based medicine: bridge-building a medicine of meaning. J Eval Clin Pract 2002, 8:103-8.

10. Guyatt GH, Meade MO, Jaeschke RZ, Cook DJ and Haynes RB: Practitioners of evidence based care. Not all clinicians need to appraise evidence from scratch but all need some skills. BMJ 2000, 320:954-5.

11. Haynes RB, Devereaux PJ and Guyatt GH: Physicians' and patients' choices in evidence based practice. BMJ 2002, 324: 1350.

12. Strauss AL and Corbin J: Basics of qualitative research: Grounded theory procedures and techniques. Newbury Park, CA: Sage 1990.

13. Glaser B and Strauss A: The discovery of grounded theory: Strategies for qualitative research. New York: Aldine de Gruyter 1967.

14. College of Family Physicians of Canada: The Janus project: family physicians meeting the needs of tomorrow's society. Toronto: College of Family Physicians of Canada 2002.

15. McColl A, Smith H, White P and Field J: General practitioner's perceptions of the route to evidence based medicine: a questionnaire survey. $B M J$ 1998, 316:36I-5.

16. Mayer J and Piterman L: The attitudes of Australian GPs to evidence-based medicine: a focus group study. Fam Pract 1999, 1 6:627-32.

17. Young JM, Glasziou P and Ward JE: General practitioners' self ratings of skills in evidence based medicine: validation study. BMJ 2002, 324:950-I.

18. Young JM and Ward JE: Evidence-based medicine in general practice: beliefs and barriers among Australian GPs. J Eval Clin Pract 200I, 7:20I-I0.

19. Freeman $A C$ and Sweeney K: Why general practitioners do not implement evidence: qualitative study. BMJ 200I, 323:1 I00-2

20. Cranney M, Warren E, Barton S, Gardner K and Walley T: Why do GPs not implement evidence-based guidelines? A descriptive study. Fam Pract 200I, I 8:359-63.

21. Veldhuis $M$, Wigersma $L$ and Okkes I: Deliberate departures from good general practice: a study of motives among Dutch general practitioners. Br J Gen Pract 1998, 48: 1833-6.

22. Putnam W, Twohig PL, Burge FI, Jackson LA and Cox JL: A qualitative study of evidence in primary care: what the practitioners are saying. CMAJ 2002, 166:1525-30.

23. Evidence-Based Medicine Working Group: Evidence-based medicine. A new approach to teaching the practice of medicine. JAMA 1992, 268:2420-2425.

24. Greenhalgh T: Intuition and evidence - uneasy bedfellows? $\mathrm{Br}$ J Gen Pract 2002, 52:395-400.

\section{Pre-publication history}

The pre-publication history for this paper can be accessed here:

http://www.biomedcentral.com/1471-2296/4/6/prepub

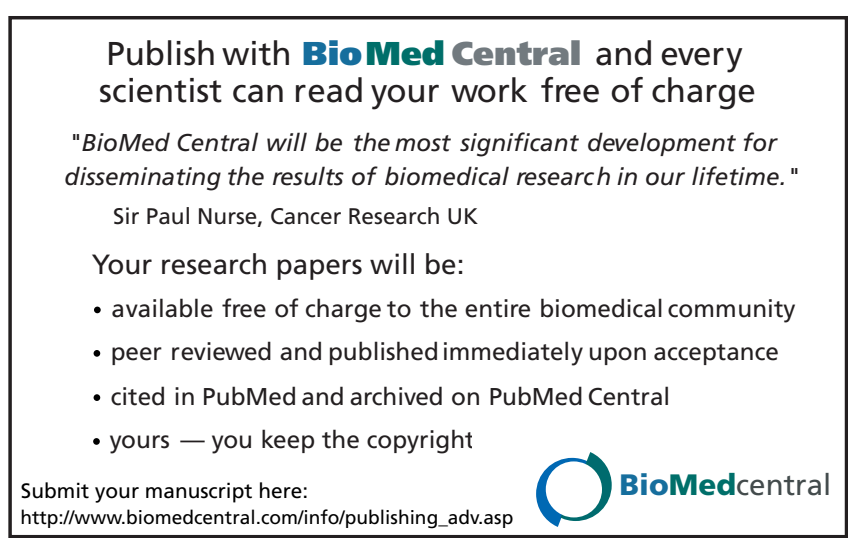

